\title{
Ku-Band High Performance Monopulse Microstrip Array Antenna Based on Waveguide Coupling Slot Array Feeding Network
}

\author{
Le ZOU, Xue-Tian WANG, Wei WANG, Wen-Yue DU \\ School of Information and Electronics, Beijing Inst. of Technology, 5 South Zhongguancun Street, Beijing 100081, China \\ zoule900818@163.com,wangxuetian@bit.edu.cn,wangwei_hhuc@126.com,mai8547@qq.com
}

Submitted September 17, 2019 / Accepted December 16, 2019

\begin{abstract}
A high gain low sidelobe monopulse microstrip array antenna for Ku-band frequency modulated continuous wave (FMCW) radar application is proposed. The design consists of microstrip array radiation front-end and waveguide coupling slot array feeding network back-end. The microstrip array comprises $16 \times 32$ series-fed patches etched on the top side and slotted ground on the bottom side. A series of shunt slots in the broad-wall are loaded on a WR51 standard magic Tee waveguide to form a compact low loss monopulse comparator and hybrid feeding network. The radiation front and feeding network is individually fabricated with standard printed circuit board (PCB) and machining process and then can be integrated by advanced assembling process. Precise alignment of waveguide slots and ground slots is obtained during these procedures to achieve accurate excitation. Measured results are in accordance with simulation results and show about $32.5 \mathrm{dBi}$ max gain and $-25 \mathrm{~dB}$ sidelobe level (SLL) of sum pattern in $E$ plane and $-27 d B$ null-depth of difference pattern at $17 \mathrm{GHz}$ center frequency.
\end{abstract}

\section{Keywords}

FMCW radar, monopulse antenna, high performance, microstrip array, waveguide coupling slot array, array feeding network

\section{Introduction}

Monopulse technology has attracted extensive concern in modern radar and communication applications. A monopulse system can offer blind-free ranging and high resolution by combining frequency modulated continuous wave (FMCW) technology with limited bandwidth [1], [2]. Therefore, a narrow band antenna can be compatible with the FMCW monopulse system.

As key component of the radio frequency (RF) section, antenna plays a significant impact on overall monopulse system performance. Reflector with four-horn feed and waveguide slots array are greatly exploited as early monopulse antenna [3-6]. However, these types of antenna usually share the features like large size and heavy weight. With the increased requirements of performance, developing high gain and highly-directional monopulse antenna with simplified configuration becomes the hotspot research in recent years. Lots of solutions have been proposed to improve existent drawbacks of conventional monopulse antenna, such as substrate integrated waveguide (SIW) slot array [7-9], corrugated multimode horn [10] and microstrip array antenna [11-14]. Among these works, the microstrip array is getting the favor of researchers owing to its characteristics of low profile, light weight and easy processing with standard PCB process. Besides, a compact monopulse comparator and feeding network with low insertion loss can heighten the overall performance promisingly [15], [16].

A self-compact monopulse antenna system with integrated comparator network is reported in [17], monopulse comparator consisting of three folded magic-tees and one $\mathrm{H}$-plane T-junction is designed. The complete system composed of radiation array front-end and comparator back-end is fabricated by introducing 3-D metal-direct-printing technology. A monopulse microstrip array antenna with SIW feeding networks is presented in [18]. However, all of these designs adopt a multi-layer structure which increases the system complexity. In addition, the insert loss of the feeding network and impedance matching can be a serious concern especially in high frequency millimeter wave applications [19].

In this article, a high gain low sidelobe monopulse microstrip antenna operating in $\mathrm{Ku}$-band with compact low loss comparator network is proposed. The system consists of microstrip array radiation front-end and waveguide coupling slot array back-end. Compared with [17], longitudinal slots are loaded on the broad wall of WR51 magic tee directly to form the back-end part. This coupled waveguide slot arrays hybrid network can act as both monopulse comparator and feeding network, so match between SIW layer and magic tee in [18] is no more needed. The amplitude and phase of each sub-array excitation can be modulated by adjusting offset distance of each corresponding waveguide slot. The entire system consists of single layer microstrip array front-end and waveguide hybrid network back-end. Such structure can be fabricated by standard PCB and ma- 
chining process respectively and then be integrated into a whole through advanced assembly technology. Both sum and difference ports are connected to standard WR51 waveguide to coaxial converter compatible with Ku-band measuring instrument or radar system. Measured results are in accordance with simulation results and verify our design.

\section{Design and Simulation}

The task of this work is generating sum and difference pattern in H-planes and sum pattern in E-planes respectively. Figure 1 shows a flowchart of detailed steps of the simulation design.

\subsection{Microstrip Array Radiation Front-end}

According to the flowchart presented in Fig. 1, the first step of design process is the synthesis of linear subarray arranged in E field direction. Taylor weighted method

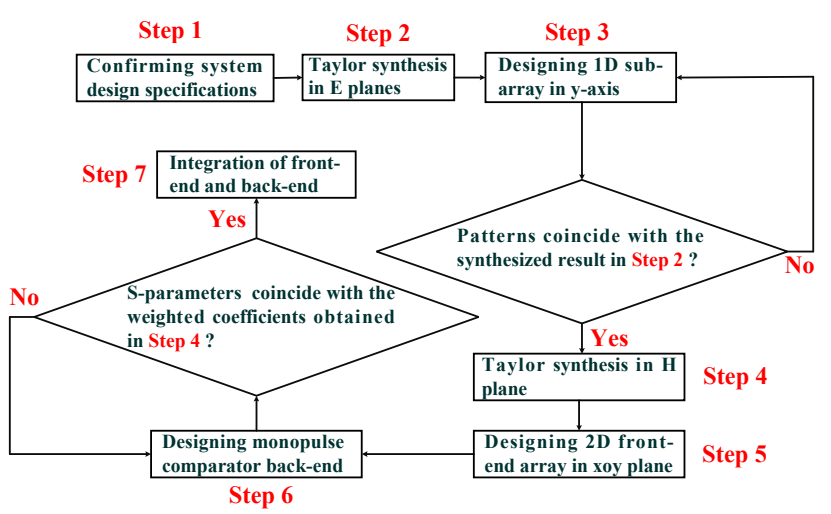

Fig. 1. Flowchart of the steps of antenna design.

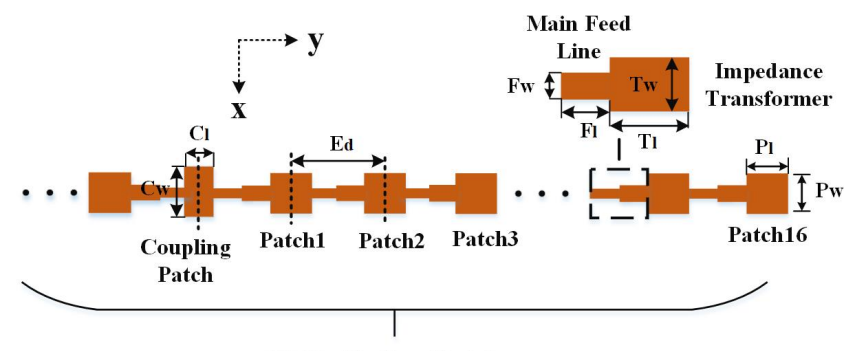

32 Radiation Patches

Fig. 2. Geometry of the designed linear sub-array.

\begin{tabular}{|c|c|c|c|c|}
\hline Parameter & $\mathbf{C}_{\mathbf{l}}$ & $\mathbf{C}_{\mathbf{w}}$ & $\mathbf{P}_{1}$ & $\mathbf{P}_{\mathbf{w}}$ \\
\hline Value (mm) & 1.92 & 6.12 & 5.59 & 6.12 \\
\hline Parameter & $\mathbf{F}_{1}$ & $\mathbf{F}_{\mathbf{w}}$ & $\mathbf{E}_{\mathbf{d}}$ & $\mathbf{T}_{\mathbf{1}}$ \\
\hline Value (mm) & 3.04 & 0.455 & 11.42 & 2.79 \\
\hline Parameter & $\mathbf{T}_{\mathbf{w} 1}$ & $\mathbf{T}_{\mathbf{w} 2}$ & $\mathbf{T}_{\mathbf{w} 3}$ & $\mathbf{T}_{\mathbf{w} 4}$ \\
\hline Value (mm) & 0.455 & 0.468 & 0.481 & 0.496 \\
\hline Parameter & $\mathbf{T}_{\mathbf{w} 5}$ & $\mathbf{T}_{\mathbf{w} 6}$ & $\mathbf{T}_{\mathbf{w} 7}$ & $\mathbf{T}_{\mathbf{w} 8}$ \\
\hline Value (mm) & 0.512 & 0.526 & 0.541 & 0.558 \\
\hline Parameter & $\mathbf{T}_{\mathbf{w} 9}$ & $\mathbf{T}_{\mathbf{w} 10}$ & $\mathbf{T}_{\mathbf{w} 11}$ & $\mathbf{T}_{\mathbf{w} 12}$ \\
\hline Value (mm) & 0.581 & 0.606 & 0.632 & 0.644 \\
\hline Parameter & $\mathbf{T}_{\mathbf{w} 13}$ & $\mathbf{T}_{\mathrm{w} 14}$ & $\mathbf{T}_{\mathbf{w} 15}$ & $\mathbf{T}_{\mathbf{w} 16}$ \\
\hline Value (mm) & 0.652 & 0.591 & 0.536 & 0.481 \\
\hline
\end{tabular}

Tab. 1. Dimensional parameters of sub-array. is used to determine the excited field distribution of each element [20]. Sidelobe level and the number of element are set to $-35 \mathrm{~dB}$ and 32 . Then a series fed microstrip linear array is modeled according to excitation obtained by Taylor synthesis. The patches are printed on the top of Rogers5880 substrate with $0.508 \mathrm{~mm}$ thickness. Quarter wavelength impedance transformers are used to achieve specific current distribution [21].

The sub-array configuration and dimension para-meters are shown in Fig. 2 and Tab. 1 respectively. Each element has the same size of patch and different size of feed line. It should be noted that both sides of the coupling patch are exactly symmetrical, so only $T_{\mathrm{wl}} \sim \mathrm{T}_{\mathrm{w} 16}$ are given in Tab. 1. The current distribution can be adjusted by varying

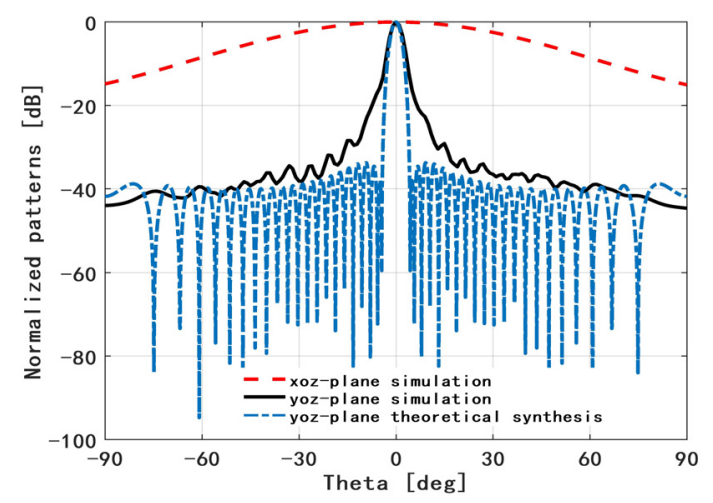

Fig. 3. Simulated normalized patterns of the designed subarray at $17 \mathrm{GHz}$ center frequency.

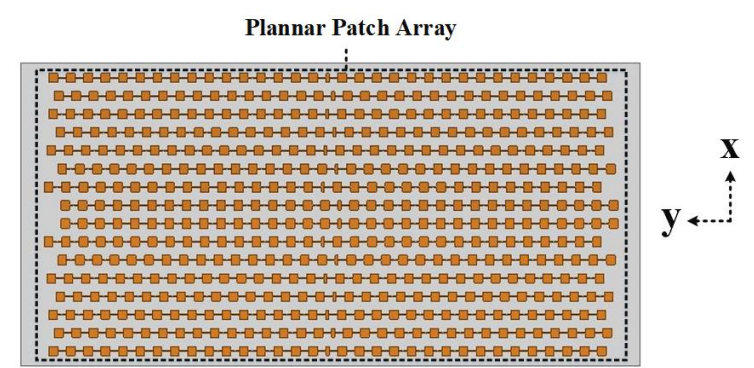

(a)

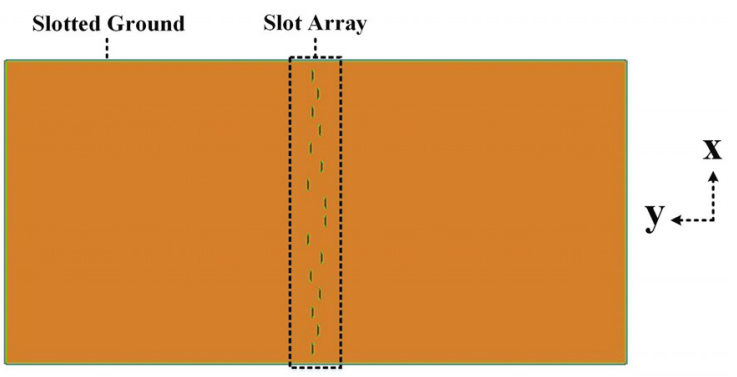

(b)

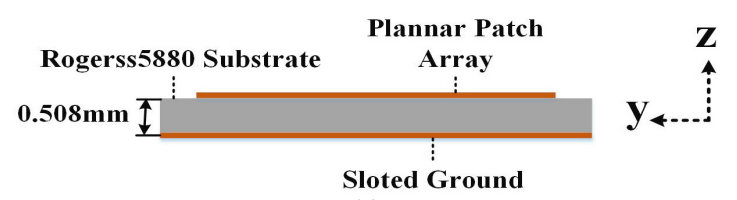

(c)

Fig. 4. Geometry of the designed planar array: (a) top view, (b) bottom view and (c) side view. 
the length and width of each transformer to form preferable radiation patterns. Figure 3 shows the synthesized and simulated patterns generated by sub-array in $\mathrm{E}$ and $\mathrm{H}$ planes. The lowest and highest frequency of FMCW signal is set to $16.9 \mathrm{GHz}$ and $17.1 \mathrm{GHz}$. In light of suppressing the external signal and the harmonic distortion, the working bandwidth of antenna is designed to be compatible with FMCW signal. All of these simulations and optimization are conducted by using Ansoft HFSS full-wave electromagnetic analysis software.

From Fig. 3, the first sidelobe level of simulation pattern in E plane gets about $-28 \mathrm{~dB}$, which degrades $7 \mathrm{~dB}$ in contrast with synthesized result. Nevertheless, the simulated and theoretical curves show a good consistency within half power beam width. Each sub-array generates weighted pattern in E plane and pattern similar to generated by single patch in $\mathrm{H}$ plane. The linear array can be extended to two-dimensional planar array by uniform alignment along the direction of $\mathrm{H}$ field. Thus weighted beam pattern in $\mathrm{E}$ and $\mathrm{H}$ planes can be obtained simultaneously. The planar array configuration is shown in Fig. 3, each column of sub-array has same shape and fed via coupled patch over the slot loaded on underlying ground plane. Precise alignment between ground slots and back-end waveguide slots must be proved to form overall feeding of patches array front-end.

\subsection{Waveguide Feeding Network Back-end}

As shown in Fig. 5(a), a series of longitudinal slots are loaded on the top wall of standard WR51 magic-T's left and right arms to compose a hybrid monopulse feeding network. The dimension parameters of back-end are listed in Tab. 2. A funnel-shaped matching stub is fixed in the center of T-junction to improve VSWR of each feeding port. The slots distribute even symmetrically about the $y$ axis and array along the $\mathrm{x}$ axis uniformly. Taylor synthesis is adopted to form weighted pattern also in $\mathrm{H}$ plane: have SLL and number of elements set to $-20 \mathrm{~dB}$ and 16 .

Excitation amplitude of each slot can be modulated by varying corresponding offset spacing related to the center line of broad wall. Adjacent slots are situated at different sides of central line and the longitudinal spacing of which are set to $\lambda_{\mathrm{g}} / 2$ (at $17 \mathrm{GHz}$ resonant frequency) to prove cophase excitation. Waveguide terminal at both ends is loaded by a slide block used in tuning. The spacing between the last slots and shorted terminal is set about $\lambda_{\mathrm{g}} / 4$ thus each slot is situated at the antinode of transverse wallcurrent.

The length and width of each slot need to be adjusted to maximize the energy coupled to the corresponding upper microstrip patch during simulation analysis. Meanwhile, amplitude and phase of coupling signal should meet the distribute regulation obtained from theoretical results. The optimization object is equivalent to regulating the transmission coefficient between waveguide input ports and microstrip output ports [22].

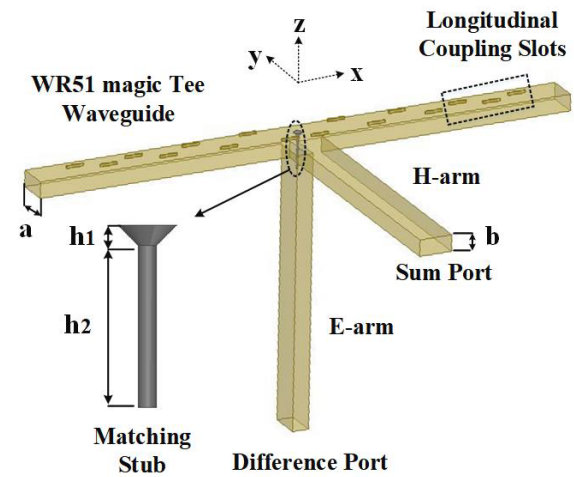

(a)

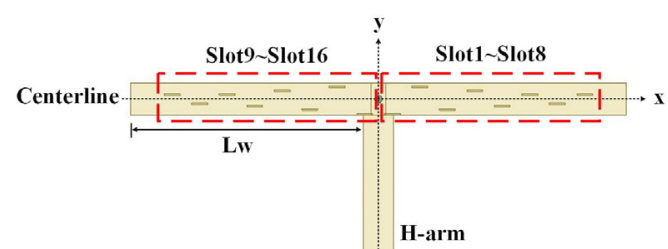

Centerline

(b)

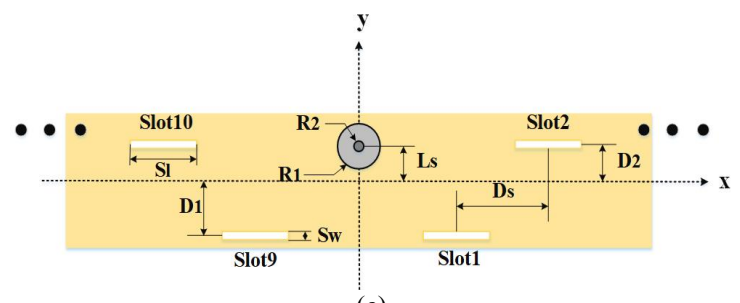

(c)

Fig. 5. Geometry of waveguide feeding network back-end and simulation optimization model: (a) slotted magic Tee back-end, (b) top view of Fig. 4(a), and (c) dimensional parameters of top broad wall.

\begin{tabular}{|c|c|c|c|c|c|}
\hline Parameter & $\mathbf{a}$ & $\mathbf{b}$ & $\mathbf{L}_{\mathbf{w}}$ & $\mathbf{L}_{\mathbf{s}}$ & $\mathbf{D}_{\mathbf{s}}$ \\
\hline Value(mm) & 12.95 & 6.48 & 101.48 & 0.4 & 12 \\
\hline Parameter & $\mathbf{h}_{\mathbf{1}}$ & $\mathbf{h}_{\mathbf{2}}$ & $\mathbf{R}_{\mathbf{1}}$ & $\mathbf{R}_{\mathbf{2}}$ & $\mathbf{S}_{\mathbf{1}}$ \\
\hline Value(mm) & 2.15 & 12.5 & 2.43 & 0.6 & 6.92 \\
\hline Parameter & $\mathbf{S}_{\mathbf{w}}$ & $\mathbf{D}_{\mathbf{1}}$ & $\mathbf{D}_{\mathbf{2}}$ & $\mathbf{D}_{\mathbf{3}}$ & $\mathbf{D}_{\mathbf{4}}$ \\
\hline Value(mm) & 0.6 & 6 & 4.95 & 4.1 & 3.4 \\
\hline Parameter & $\mathbf{D}_{\mathbf{5}}$ & $\mathbf{D}_{\mathbf{6}}$ & $\mathbf{D}_{\mathbf{7}}$ & $\mathbf{D}_{\mathbf{8}}$ & \\
\hline Value(mm) & 2.62 & 1.93 & 1.75 & 1.82 & \\
\hline
\end{tabular}

Tab. 2. Dimensional parameters of back-end.

\subsection{Antenna Configuration}

The above mentioned front-end and back-end can be integrated into a complete system, also with the overall antenna configuration. The antenna radiates weighted sum patterns in $\mathrm{E}$ and $\mathrm{H}$ planes simultaneously when signal is input into $\mathrm{H}-\mathrm{T}$ port (sum port) and difference beam in $\mathrm{H}$ plane when signal is input into E-T port (difference port).

Figure 6 shows the simulation result of patterns radiated by the proposed array antenna. As can be seen from the curves in the sketch, $30 \mathrm{dBi}$ maximum gain in sum 


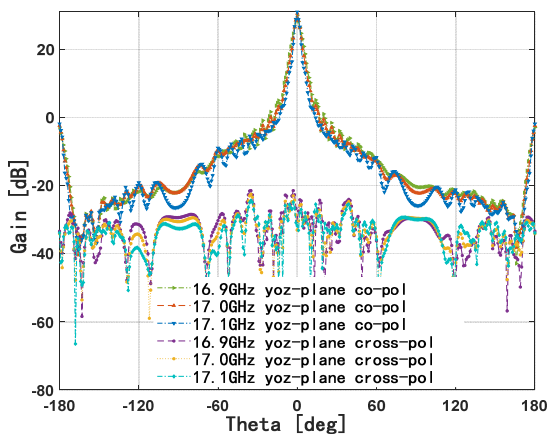

(a)

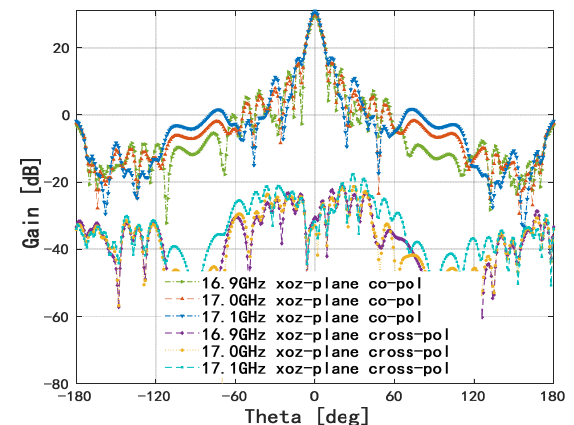

(b)

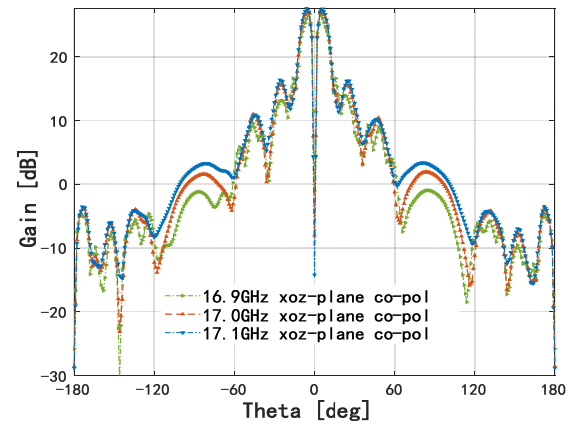

(c)

Fig. 6. Simulated gain patterns of the proposed array antenna: (a) sum patterns in yoz plane, (b) sum patterns in $\mathrm{xoz}$ plane, and (c) difference patterns in xoz plane.

patterns and $-32 \mathrm{~dB}$ nulling depth in difference patterns was achieved respectively at normal $+z$ direction. Compared with theoretical synthesis result, the deviation from SLL of sum patterns is less than $5 \mathrm{~dB}$. Besides the copolarization components, the cross-polarization level corresponding to sum patterns in $\mathrm{E}$ (yoz) and $\mathrm{H}$ (xoz) planes is lower than $-50 \mathrm{~dB}$, which is acceptable to practical applications.

Figure 7 is the simulation results of E-field and current vectors distribution on the surface of front-end patches. These results can also interpret the curves in Fig. 6: when excitation is fed into the sum port, currents of sub-arrays located in positive and negative $\mathrm{x}$ axis flow in a consistent direction, so the radiation field generated by both parts superposes in same phase and achieves maximum intensity at $+\mathrm{z}$ direction. While the excitation is fed into the difference port, currents on each sides are in reverse direction, then the radiation field undergoes an out-of-phase superposition and achieves minimum intensity (nulling depth) at $+\mathrm{z}$ direction.

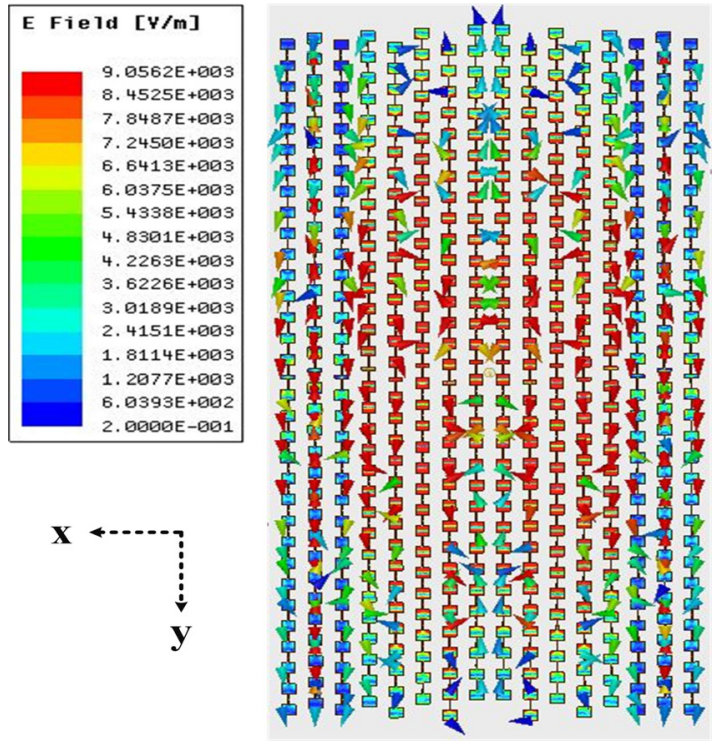

(a)

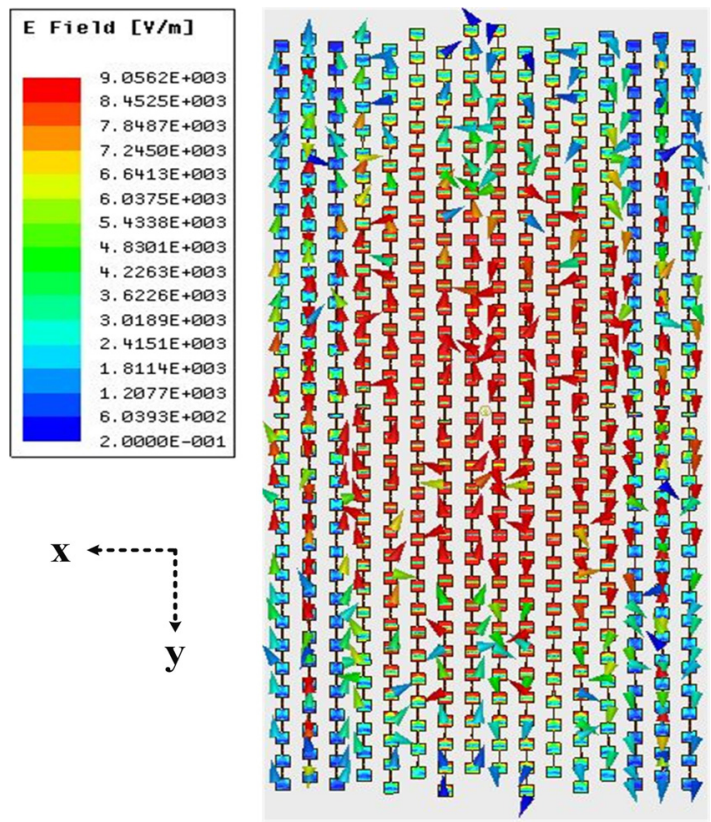

(b)

Fig. 7. Simulated E-field and surface current distributions of the proposed array antenna at $17 \mathrm{GHz}$ : (a) The excitation is put on the sum port of magic $\mathrm{T}$ feeding network. (b) The excitation is put on the difference port of magic-T feeding network.

\section{Fabrication and Measurement}

The power transmits between front-end and back-end via coupling slots. As to physical processes, the fabrication technology is the main focus of our concern. For the microstrip array antenna in monopulse radar system, there are general requirements of compact structure, high integration with transceiver and being facilitated as a whole layout in order to be precisely controlled by the servo system. Hence, this design has severe demands for processing technology: it's necessary to achieve a high flatness of the front-end with large aperture to produce ideal beam patterns. What's 
more, the accurate connection between back and front end is also a serious issue in this work.

\subsection{Processing Technology}

The front and back ends are processed separately by standard PCB technology and machining operation, then the two segments are integrated together by advanced assembling process. Since this craftwork satisfies the requirement of systematic machining accuracy, the method of machining the back and front-end as an entire configuration by $3 \mathrm{D}$ printing technology like [17] is not adopted. Figure 8 shows the processing of microstrip board and coupled waveguide. The main arm of H-T section is added a $90^{\circ}$ bending section to be parallel with E-T's main arm as long as $30 \mathrm{~mm}$. The sum and difference ports corresponding to $\mathrm{H}-\mathrm{T}$ and $\mathrm{E}-\mathrm{T}$ have the same $\mathrm{z}$ coordinates.

\subsection{Integration and Assembling}

As to the integration of front and back-end, accurate alignments between waveguide slots and ground slots as well as high flatness of microstrip array are the two main aspects of interest. Figure 9 shows the photograph of the

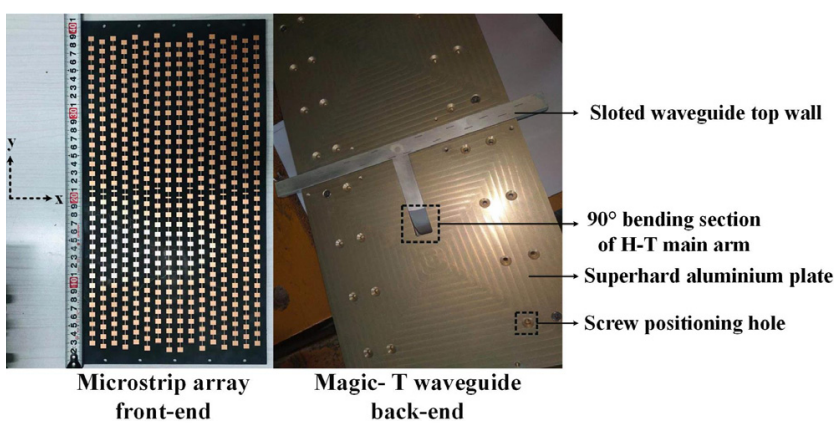

Fig. 8. Photograph of the fabricated microstrip array front-end and coupling magic $\mathrm{T}$ waveguide back-end.

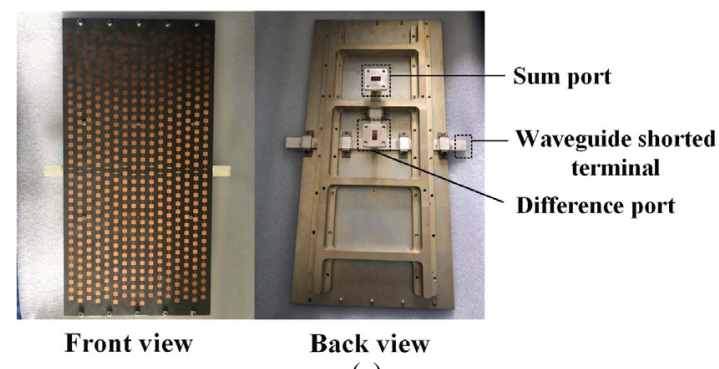

(a)
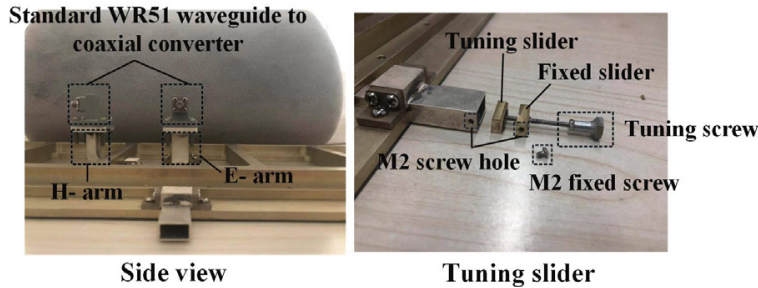

(b)

Fig. 9. Photograph of the fabricated antenna configuration and tuning slider: (a) front and back view, (b) side view and tuning slider. fabricated antenna assembly structure: WR51 waveguide with $12.954 \times 6.477 \mathrm{~mm}^{2}$ cross-sectional area and superhard aluminum plate of $4 \mathrm{~mm}$ thick with the same size as the front-end are rigidly connected as an entirety. High precision machining technology can ensure that the top wall of the waveguide and surface of the superhard aluminum plate are on the same plane to prove high flatness. Besides, a series of $0.3 \mathrm{~mm}$ diameter positioning pin holes is drilled through the microstrip substrate and the hard aluminum plate to ensure precise alignment. The front-end is pasted on superhard aluminum plate by using insulating glue, then the pins are inserted into positioning holes and the glue is cured by high temperature baking process.

\subsection{Adjustment and Measurement}

The waveguide terminals are set as electrical wall in simulation model. While for the fabricated prototype, the short circuit condition is achieved by inserting tuning slider shown in Fig. 9 into both terminals. Adjustment of impedance matching followed in this procedure: twisting the screw of both sliders and observing the changing of reflection coefficient simultaneously. The inserted depths of both left and right ends need to be same so as to make symmetrical field distribution in waveguide cavity. The modulated results of S-parameters of the proposed antenna measured by Agilent-N5246A PNA-X network analyzer are shown in Fig. 10.

The radiation patterns are measured under the condition of fixed insertion depth of each tuning slider shown in Fig. 9. The test is conducted in anechoic chamber with near field scanning method. Measured normalized patterns at $17 \mathrm{GHz}$ central operating frequency are given in Fig. 11.

\subsection{Analysis and Discussion}

The experimental results suffer the influence of manufacturing errors. In addition, there are some other key factors needed to be taken into account. This section is a rigorous analysis and discussion of these factors.

From the presented results of Fig. 10, measured reflection coefficient of both ports is less than $-10 \mathrm{~dB}$ and

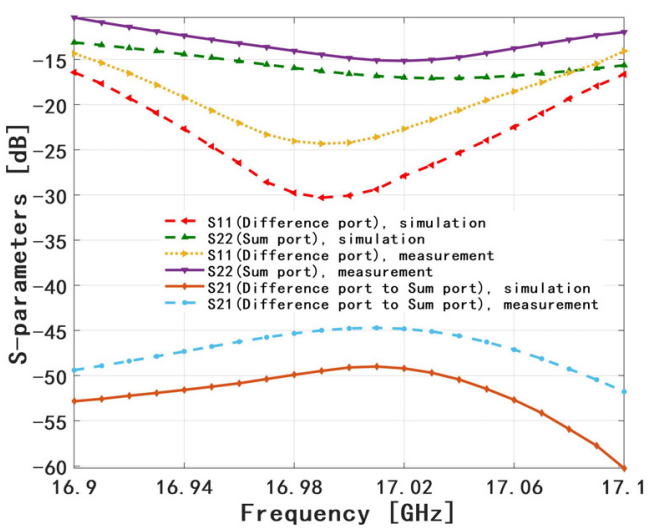

Fig. 10. Simulated and measured reflection coefficients of the proposed antenna. 


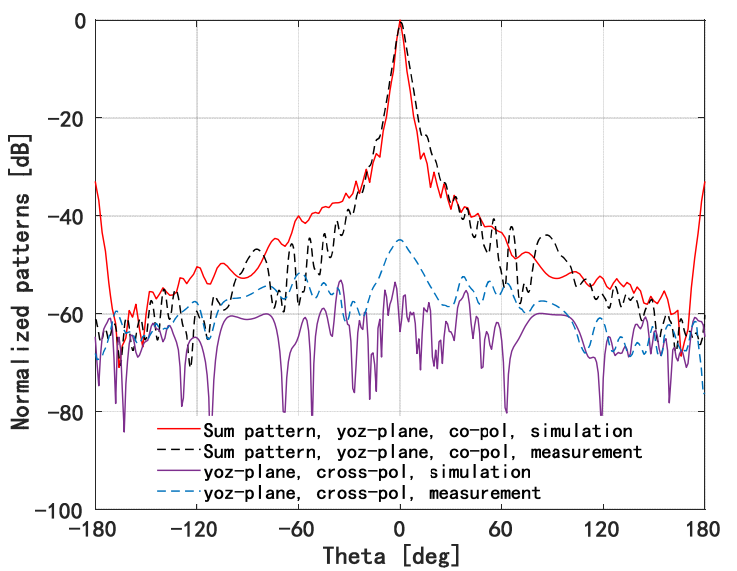

(a)

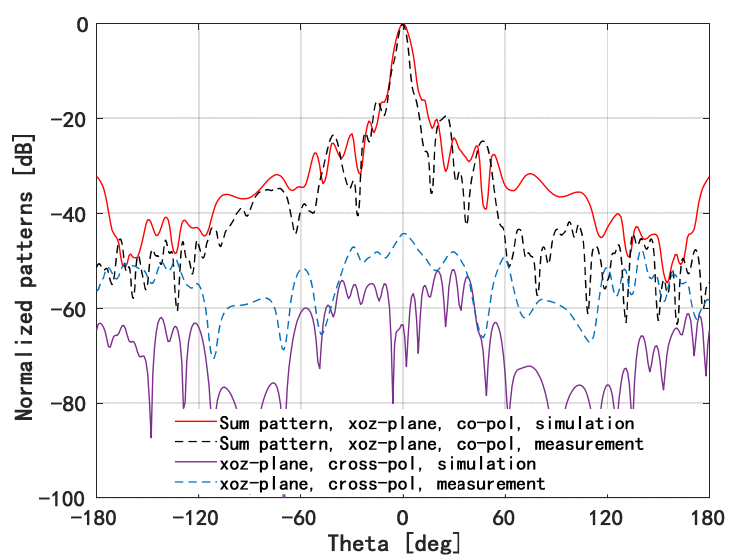

(b)

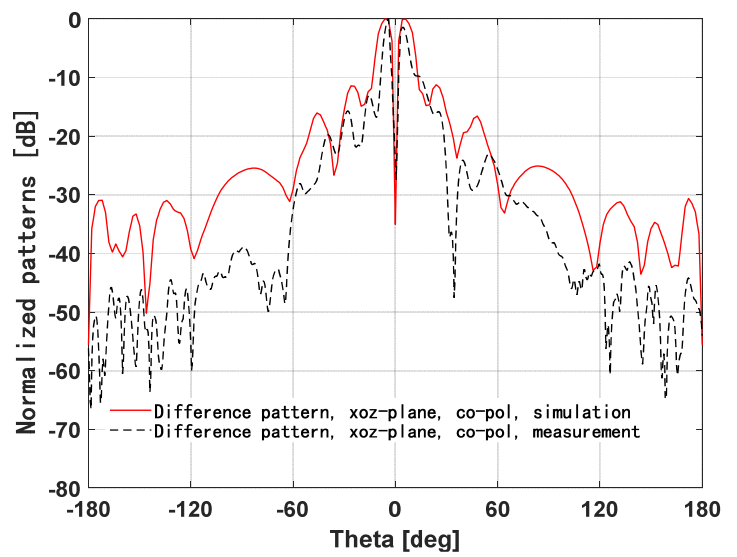

(c)

Fig. 11. Simulated and measured normalized patterns of the proposed antenna at $17 \mathrm{GHz}$ central operating frequency. (a) Sum patterns in yoz plane, (b) sum patterns in xoz plane and (c) difference patterns in xoz plane.

isolation between the two ports is below $-45 \mathrm{~dB}$ in the operational band. Compared with simulation curves, measured reflection coefficients deteriorate about $2 \mathrm{~dB}$ on sum port and $6 \mathrm{~dB}$ on difference port at $17 \mathrm{GHz}$ central frequency where the measured $S_{11}$ and $S_{22}$ can reach $-24 \mathrm{~dB}$ and $-15 \mathrm{~dB}$ respectively. This is mainly due to the impact of processing conditions: the front-end ground and waveguide top wall coincide in simulation modal, while there exist insulating adhesive layer with about $0.5 \mathrm{~mm}$ thickness between the substrate and aluminum plate in prototype. The glue around the slots is scraped off, which leads to irregularities of the adhesive layer, hence influencing the power coupling from back to front end negatively and worsen the matching performance of both ports.

As to the sum patterns in Fig. 11(a), (b), $32.5 \mathrm{dBi}$ maximum gain is achieved from the measurement result. The measured first SLL of sum patterns in $\mathrm{E}(\mathrm{yoz})$ and $\mathrm{H}(\mathrm{xoz})$ planes at focused frequency points is about $-25 \mathrm{~dB}$ and $-17 \mathrm{~dB}$. The $3 \mathrm{~dB}$ beam width reaches the value of $2.8^{\circ}$ in E plane and $5^{\circ}$ in $\mathrm{H}$ plane approximately. The measured relative amplitude of cross-polarization field is shown to be $-44 \mathrm{~dB}$ at $+\mathrm{z}$ direction. For the difference beam in Fig. 11(c), the measured maximum nulling depth turns to be $-27 \mathrm{~dB}$, whereas the simulated one is $-34 \mathrm{~dB}$. All of these results indicate the deterioration compared to the simulated ones. The main explanations of these appearances are errors caused by integration of whole antenna structure and the constraints of near-field measurement system. What's more, the sub-arrays located at $+x$ and $-x$ axis may suffer an asymmetric excitation due to the difficulties in assuring each tuning slider has the same inserted depth at both terminals, which contributes to asymmetry of measured difference pattern shown in Fig. 11(c) mostly. Besides, the previously mentioned adhesive layer which would degrade the flatness of front-end as well as limited test instrument system accuracy contribute to flaws in this work.

Compared with the simulated maximum gain, the measured result decreases by about $3 \mathrm{~dB}$. The reason for this phenomenon is varied. The dielectric constant and loss tangent of Rogers5880 substrate in HFSS is $2.2 \pm 0.02$ and 0.0009 at $10 \mathrm{GHz}$, while at $17 \mathrm{GHz}$ operational band the dielectric loss will be much greater. Although the loss of back-end is very low, assembly processes during integration will inevitably cause some losses. A comparison between some published works and this work is presented in Tab. 3.

Since the proposed structure adopts compact magic-T waveguide back-end network with low loss like [15], [17], preferable isolation and gain performance can be achieved. It's noted that narrow beam is generated by Taylor synthesis of front-end array in this design. So the radar can take aim at target without reflector antenna applied in traditional monopulse system. Although the impedance characteristics meet the application requirements, there is still room for improvement in bandwidth. Nevertheless, a compact slotted magic-T waveguide acts as feeding network entirety instead of combined feeding structure with transition of waveguide to SIW in early published [18], the complexity of configuration is further reduced and loss of back-end are decreased then the gain are enhanced. Hence the overall performance of the antenna system is promoted promisingly. In the subsequent work, this prototype design can be applied in some higher frequency millimeter wave (MMW) scenarios, such as W-band monopulse radar system. 


\begin{tabular}{|c|c|c|c|c|c|c|c|c|}
\hline \multirow[b]{2}{*}{ Ref. } & \multicolumn{2}{|c|}{ Structure and manufacturing } & \multicolumn{2}{|c|}{ Impedance Characteristics } & \multicolumn{4}{|c|}{ Radiation Characteristics } \\
\hline & Comparator & Antenna & $\begin{array}{c}\text { Operating } \\
\text { band } \\
\left(S_{11}<-10 \mathrm{~dB}\right)\end{array}$ & Isolation & Gain & $\begin{array}{c}\text { First side lobe } \\
\text { level }\end{array}$ & $\begin{array}{c}\text { Cross } \\
\text { polarization } \\
\text { level }\end{array}$ & $\begin{array}{l}\text { Nulling } \\
\text { depth }\end{array}$ \\
\hline \multirow[t]{2}{*}[7]{} & SIW magic-T & $\begin{array}{c}\text { SIW slot } \\
\text { array }\end{array}$ & \multirow[t]{2}{*}{$57.48 \sim 64 \mathrm{GHz}$} & \multirow[t]{2}{*}{$25 \mathrm{~dB}$} & \multirow[t]{2}{*}{$15.8 \mathrm{dBi}$} & \multirow[t]{2}{*}{$-9 \mathrm{~dB}$} & \multirow[t]{2}{*}{$-25 \mathrm{~dB}$} & \multirow[t]{2}{*}{$-31 \mathrm{~dB}$} \\
\hline & \multicolumn{2}{|c|}{ PCB } & & & & & & \\
\hline \multirow[t]{2}{*}{ [10] } & waveguide network & $\begin{array}{l}\text { corrugated } \\
\text { multimode } \\
\text { horn }\end{array}$ & \multirow[t]{2}{*}{$15.9 \sim 16.3 \mathrm{GHz}$} & \multirow[t]{2}{*}{$35 \mathrm{~dB}$} & \multirow[t]{2}{*}{$21.1 \mathrm{dBi}$} & \multirow[t]{2}{*}{$-28 \mathrm{~dB}$} & \multirow[t]{2}{*}{$-45 \mathrm{~dB}$} & \multirow[t]{2}{*}{$-25 \mathrm{~dB}$} \\
\hline & \multicolumn{2}{|c|}{ machining } & & & & & & \\
\hline \multirow[t]{2}{*}[15]{} & $\begin{array}{l}\text { gap waveguide } \\
\text { magic-T }\end{array}$ & $\begin{array}{c}\text { plate slot } \\
\text { array }\end{array}$ & \multirow[t]{2}{*}{$85 \sim 102 \mathrm{GHz}$} & \multirow[t]{2}{*}{$50 \mathrm{~dB}$} & \multirow[t]{2}{*}{$30.5 \mathrm{dBi}$} & \multirow[t]{2}{*}{$-20 \mathrm{~dB}$} & \multirow[t]{2}{*}{$-27 \mathrm{~dB}$} & \multirow[t]{2}{*}{$-40 \mathrm{~dB}$} \\
\hline & \multicolumn{2}{|c|}{ machining } & & & & & & \\
\hline \multirow[t]{2}{*}{ [17] } & waveguide network & $\begin{array}{c}\text { plate slot } \\
\text { array }\end{array}$ & \multirow[t]{2}{*}{$14.15 \sim 16.1 \mathrm{GHz}$} & \multirow[t]{2}{*}{$30 \mathrm{~dB}$} & \multirow[t]{2}{*}{$31.5 \mathrm{dBi}$} & \multirow[t]{2}{*}{$-14 \mathrm{~dB}$} & \multirow[t]{2}{*}{$-30 \mathrm{~dB}$} & \multirow[t]{2}{*}{$-37 \mathrm{~dB}$} \\
\hline & \multicolumn{2}{|c|}{ 3-D printing } & & & & & & \\
\hline \multirow[t]{2}{*}[18]{} & magic-T, sloted SIW & $\begin{array}{c}\text { microstrip } \\
\text { array }\end{array}$ & $93 \sim 96 \mathrm{GHz}$ & $\begin{array}{c}\text { Not } \\
\text { available }\end{array}$ & $26.63 \mathrm{dBi}$ & $\begin{array}{l}-26.4 \mathrm{~dB} \text { in E-plane, } \\
-13.3 \mathrm{~dB} \text { in H-plane }\end{array}$ & $\begin{array}{c}\text { Not } \\
\text { available }\end{array}$ & $-28.9 \mathrm{~dB}$ \\
\hline & machining, PCB & PCB & & & & & & \\
\hline$[23]$ & ring coupler & $\begin{array}{c}\text { planar Yagi } \\
\text { array }\end{array}$ & $24 \sim 32 \mathrm{GHz}$ & $30 \mathrm{~dB}$ & $14 \mathrm{dBi}$ & $-14 \mathrm{~dB}$ in E-plane, & $-34 \mathrm{~dB}$ & $-28 \mathrm{~dB}$ \\
\hline & PCB & & & & & $-7 \mathrm{~dB}$ in H-plane & & \\
\hline This & sloted magic- $\mathrm{T}$ & $\begin{array}{c}\text { microstrip } \\
\text { array }\end{array}$ & $16.9 \sim 17.1 \mathrm{GHz}$ & $45 \mathrm{~dB}$ & $32.5 \mathrm{dBi}$ & $-25 \mathrm{~dB}$ in E-plane, & $-44 \mathrm{~dB}$ & $-27 \mathrm{~dB}$ \\
\hline work & machining & PCB & & & & & & \\
\hline
\end{tabular}

Tab. 3. Comparison with some previous designs of monopulse antennas.

\section{Conclusion}

This paper proposes a Ku-band high gain low sidelobe monopulse microstrip array antenna. Taylor synthesis method is used to form sum patterns in both $\mathrm{E}$ and $\mathrm{H}$ planes. A series of specific weight coefficients are achieved by varying the size of each impedance transformer and offset spacing of each slots. $32 \times 16$ rectangular paths composed of the microstrip front-end. The antenna has a compact low loss waveguide back-end in which monopulse comparator itself acts as feeding network. The manufacturing process and flow routes are particularly introduced. This prototype can be finished by advanced assembly technology. Measured maximum gain of sum patterns and minimum nulling depth of difference patterns reaches $32.5 \mathrm{dBi}$ and $-27 \mathrm{~dB}$ respectively at $17 \mathrm{GHz}$ central operating frequency. Measured results are in accordance with simulation results and verify our design. This prototype can be applied in high performance narrowband monopulse radar system for suppressing out-band interferes or in higher frequency MMW scenarios.

\section{References}

[1] WANG, S., TSAI, K. H., HUANG, K. K., et al. Design of X-band $\mathrm{RF}$ CMOS transceiver for $\mathrm{FMCW}$ monopulse radar. IEEE Transactions on Microwave Theory and Techniques, 2009, vol. 57 no. 1, p. 61-70. DOI: 10.1109/TMTT.2008.2008942
[2] MAHAFZA, B. R., ELSHERBENI, A. Z. MATLAB Simulations for Radar Systems Design. ${ }^{\text {st }}$ ed., rev. New York (US): Chapman and Hall/CRC, 2003. (Radar Waveforms, p. 157-202) ISBN: 1584883928

[3] SKOLNIK, M. I. Introduction to Radar Systems. 3rd ed., rev. McGraw-Hill Education, 2003. (Monopulse Tracking Radar, p. 160-167) ISBN: 0072881380

[4] JAKOBY, R. A novel quasi-optical monopulse-tracking system for millimeter-wave application. IEEE Transactions on Antennas and Propagation, 1996, vol. 44, no. 4, p. 466-477. DOI: $10.1109 / 8.489298$

[5] LING, C. C., REBEIZ, G. M. 94 GHz integrated horn monopulse antennas. IEEE Transactions on Antennas and Propagation, 1992, vol. 40, no. 8, p. 981-984. DOI: 10.1109/8.163437

[6] KELly, K. C., GOEBELS, F. J. Annular slot monopulse antennas. IEEE Transactions on Antennas and Propagation, 1964, vol. 12, no. 4, p. 391-403. DOI: 10.1109/TAP.1964.1138263

[7] ZHU, J. F., LIAO, S. W., LI, S. F., XUE, Q. 60 GHz substrateintegrated waveguide-based monopulse slot antenna arrays. IEEE Transactions on Antennas and Propagation, 2018, vol. 66, no. 9 , p. 4860-4865. DOI: 10.1109/TAP.2018.2847324

[8] CAO, F. F., YANG, D. G., PAN, J., et al. A compact single-layer substrate-integrated waveguide (SIW) monopulse slot antenna array. IEEE Antennas and Wireless Propagation Letters, 2017, vol. 16, p. 2755-2758. DOI: 10.1109/LAWP.2017.2744668

[9] CHENG, Y. J., HONG, W., WU, K. 94 GHz substrate integrated monopulse antenna arrays. IEEE Transactions on Antennas and Propagation, 2012, vol. 60, no. 1, p. 121-129. DOI: 10.1109/TAP.2011.2167945

[10] ZHANG, H. Z., GRANET, C., SPREY, M. A. A compact Ku-band monopulse horn. Microwave and Optical Technology Letters, 2002, vol. 34, no. 1, p. 9-13. DOI: $10.1002 /$ mop. 10357 
[11] WANG, H., FANG, D. G., CHEN, X. G. A compact single layer monopulse microstrip antenna array. IEEE Transactions on Antennas and Propagation, 2006, vol. 54, no. 2, p. 503-509. DOI: 10.1109/TAP.2005.863103

[12] HUANG, H. Y., WANG, B. Z., LI, F., et al. A Ka-band monopulse microstrip antenna array. In IEEE MTT-S International Microwave Workshop Series on Art of Miniaturizing $R F$ and Microwave Passive Components (IMWS). Chengdu (China), 2008, p. 124-127. DOI: 10.1109/IMWS.2008.4782278

[13] KIM, S. G., CHANG, K. Low-cost monopulse antenna using bidirectionally-fed microstrip patch array. Electronics Letters, 2003, vol. 39, no. 20, p. 1428-1429. DOI: 10.1049/el:20030963

[14] XU, Q., SUN, H. J., YANG, H. Z., et al. A digital sum-difference millimeter wave monopulse system based on microstrip array antenna. In 20th Asia Pacific Microwave Conference (APMC 2008). Hong Kong (China), 2008, p. 97-100. DOI: 10.1109/APMC.2008.4957876

[15] VOSOOGH, A., HADDADI, A., ZAMAN, A. U., et al. W-band low-profile monopulse slot array antenna based on gap waveguide corporate-feed network. IEEE Transactions on Antennas and Propagation, 2018, vol. 66, no. 12, p. 6997-7009. DOI: $10.1109 /$ TAP.2018.2874427

[16] LIU, Y., YANG, H., HE, Y., ZHU, J. Compact monopulse sumdifference comparator based on double-layer substrate integrated waveguide. Electronics Letters, 2017, vol. 53 no. 22 p. 1477-1478. DOI: 10.1049/el.2017.2064

[17] HUANG, G. L., ZHOU, S. G., CHIO, T. H. Highly-efficient selfcompact monopulse antenna system with integrated comparator network for RF industrial applications. IEEE Transactions on Industrial Electronics, 2017, vol. 64, no. 1, p. 674-681. DOI: 10.1109/TIE.2016.2608769

[18] WANG, W., ZOU, L., WANG, X. T. A novel 94 GHz planar integrated monopulse array antenna with hybrid feeding networks. IEICE Electronics Express, 2018, vol. 15, no. 12, p. 1-9. DOI: 10.1587/elex.15.20180381

[19] KUMAR, H., KUMAR, G. Monopulse comparators. IEEE Microwave Magazine, 2019, vol. 20, no. 3, p. 13-23. DOI: 10.1109/MMM.2018.2885670

[20] ALVAREZ-FOLGUEIRAS, M., RODRIGUEZ-GONZALEZ, J. A., ARES-PENA, F. Synthesising Taylor and Bayliss linear distributions with common aperture tail. Electronics Letters, 2009, vol. 45 , no. 1 , p. $18-19$. DOI: 10.1049/el:20093322

[21] HUANG, J. A parallel series fed microstrip array with high efficiency and low cross polarization. Microwave and Optical Technology Letters, 1992, vol. 5, no. 5, p. 230-233. DOI: 10.1002/mop.4650050509
[22] RAO, J. S., JOSHI, K. K., DAS, B. N. Analysis of small aperture coupling between rectangular waveguide and microstrip line. IEEE Transactions on Microwave Theory and Techniques, 1981, vol. 29, no. 2, p. 150-154. DOI: 10.1109/TMTT.1981.1130312

[23] NIE, X. H., HONG, W., FAN, K. K. Monopulse array and low side-lobe level array with a novel feed network. IET Microwaves, Antennas \& Propagation, 2018, vol. 12, no. 12, p. 1978-1985. DOI: 10.1049 /iet-map.2018.5212

\section{About the Authors ...}

Le ZOU was born in Beijing, China in 1990. He received the B.Sc. from the Yanshan University, Qinhuangdao, China, in 2013, and M.Sc. degrees from the Beijing University of Posts and Telecommunications, Beijing, China, in 2017. He is currently doing his Ph.D. Programme in the School of Information and Electronics, Beijing Institute of Technology. His research interests include antenna theory and design, MMW radar technology, and the monopulse detection system.

Xue-Tian WANG was born in Jiangsu Province, China in 1963. He received the B.Sc. and Ph.D. degrees in Electronic Engineering from the Beijing Inst. of Technology, Beijing, China, in 1986 and 2002, respectively. He is currently a full Professor with the School of Information and Electronics, Beijing Institute of Technology. His research interests include antenna design and EMC technology.

Wei WANG was born in Jiangsu Province, China in 1989. He received the B.Sc. from the Hohai University, Nanjing, China, in 2011, and Ph.D. degrees from the Beijing Institute of Technology, Beijing, China, in 2018. His research interests include antenna theory and design, and EMC technology.

Wen-Yue DU was born in Jilin Province, China in 1994. She received the B.Sc. from the Beihua University, Jilin, China, in 2016, and M.Sc. degrees from the Beijing Institute of Technology, Beijing, China, in 2019. Her research interests include antenna theory and design, and MMW radar system. 